\title{
Students' Acceptance and Perceptions of Perceived Usefulness of Mobile Learning Devices in Higher Educational Institutions
}

\author{
John Edumadze 1 \\ (D) 0000-0002-6827-5268
}

Gopolang Ditlhokwa 2*

(D) 0000-0002-1876-7715

\author{
John Demuyakor ${ }^{2}$ \\ (D) 0000-0002-6084-6951 \\ ${ }^{1}$ School of Philosophy, Beijing Normal University, Beijing, CHINA \\ ${ }^{2}$ Institute of Communication Studies, Communication University of China, Beijing, CHINA \\ *Corresponding author: gditlhokwa@hotmail.com
}

Citation: Edumadze, J., Ditlhokwa, G., \& Demuyakor, J. (2022). Students' Acceptance and Perceptions of Perceived Usefulness of Mobile Learning Devices in Higher Educational Institutions. Online Journal of Communication and Media Technologies, 12(2), e202209. https://doi.org/10.30935/ojcmt/11539

\section{ARTICLE INFO}

Received: 29 Nov 2021

Accepted: 7 Jan 2022

\section{ABSTRACT}

As technology-mediated innovations like Mobile Learning Devices (MLDs) spread rapidly across the globe, there are growing concerns on the actual factors that influence students in Higher Educational institutions (HEls) to accept technology-mediated innovations like smartphones, tablets, and portable computing devices for their educational pursuit. This study adopted Technology Acceptance Model (TAM) as a theoretical basis in an attempt to investigate factors that might influence students to accept or decline the use of technology-mediated innovations specifically MLDs for academic purposes from the perspectives of three universities in Ghana. A set of online questionnaire survey was used to collect the needed data from $(\mathrm{N}=1,030)$ students. The researchers also conducted data analysis and presentation of findings by testing the suggested research model through Structural Equation Modelling. A regression analysis was also carried out with the help of SmartPLS to assess the path coefficient of the data collected for the model. This study identified influencing factors such as students' awareness levels, m-learning technology types, perceived ease of use, and perceived usefulness as some of the central factors that determine how students use and accept m-learning devices in Ghanaian universities. The study reported limitations such as expensive internet data, poor internet infrastructure, insecurity, privacy issues, and unavailability of electricity as some of the factors limiting the acceptance of MLDs by students in Ghana. Despite the limitations reported in this study, the results from the statistical analysis, show that there are high levels of MLDs acceptance among students from the three sampled higher educational institutions in Ghana. The study recommends that school authorities and governments in developing countries such as Ghana incorporate MLDs in their current higher educational systems.

Keywords: higher educational institutions; mobile learning devices; technology-mediated, innovations, Ghana

\section{INTRODUCTION}

As highlighted by Okoye et al. (2021), and Ontiveros and Pazos (2013), technology-driven innovations are today transforming the old learning methods or techniques, generating several new learning dimensions for teachers and learners. Indeed, according to Ahmad (2020), and Vázquez Cano and Sevillano-García (2018), mobile phones and smart devices have taken over our entire lives, starting from entertainment and general communication, to the way learning is conducted. Devices supporting mobile learning within higher learning are greatly transforming learning, especially for the digital natives. Apuke and lyendo (2018) report that a 
study revealed that $86 \%$ of college university learners today possess at least a smart device, with nearly half of the students utilizing their respective mobile devices to accomplish their day-to-day academic work, which has greatly improved the academic outcomes of students.

Further, a recent report by Mpungose (2020), and Sharma et al. (2016) also state that hand-held devices, such as tablets and smartphone devices, are currently the most favored gadgets used in accessing the internet and comprising of more than $50 \%$ of all browsing activity globally. These particular statistics support the beginning of a remarkable trend as regards the use of mobile learning gadgets within higher education. As noted by UNESCO (2015), these devices aid in terms of educational content delivery, particularly by utilizing mobile technology, including tablets and smartphone devices, which are acquiring increasing popularity within the higher education sector. Indeed, their increasing use has recently become a major subject of numerous discussions within higher learning institutions.

Mobile learning devices including smartphones and tablet use in Ghana, started at a slow rate, just like in many African countries, but has grown and expanded to both urban and rural areas in Ghana over the past decade (Kankam, 2020). The impact of mobile learning devices on the output of the students in higher education institutions in Ghana can never be underestimated. Mobile learning devices have enabled students to interact and network on a wide range of issues. They use mobile learning devices as an avenue for the exchange of learning experiences, knowledge, academic opportunities, and even sharing research findings (Chand \& Arora, 2008; Kankam, 2020; Sharma et al., 2016). Increased access to the internet has made it much easier for faculty members and students to join various mobile learning devices such as the internet or network that make use of personal mobile devices like smartphones, tablets, laptops, and digital notebooks. Various scholars assign reasons to justify the use of mobile learning devices for academic purposes. The transformative power of mobile learning devices allows students and researchers within academia to have exposure to the rest of the world (Kankam, 2020; Peters, 2007). This will promote networking, sharing of expertise, and attracting new audiences (Criollo-C et al., 2018; Kankam, 2020). This study is aimed at evaluating factors that influence students' acceptance, and perceptions of the perceived usefulness of mobile learning devices from three convenient sampled universities in Ghana.

\section{LITERATURE REVIEW: THEORETICAL FRAMEWORK AND DEVELOPMENT OF RESEARCH MODEL}

\section{Awareness, Knowledge, and Types of M-Learning Devices and Technologies in Higher Educational Institutions}

The traditional learning concept has been transformed drastically. According to Mohammadi et al. (2020), with the growing acquisition of the Internet as well as the new technologies, accessing quality online education by utilizing a computer as well as web connection is possible. Indeed, it is a technological period that has witnessed mobile learning within higher education not only becoming quite common but also a significantly revolutionary concept as well. According to Sung et al. (2016) adopting mobile learning devices and technologies within higher education is very useful to both teachers and learners.

Indeed, as stated by Alzaza and Yaakub (2011), and Okoye et al. (2021), whatever region of the world individuals find themselves in, whether, within a developing or a developed nation-learning within higher learning can always aid members of a faculty not only sharpening their respective research skills as well as growing their careers but also their overall productivity (see also Mahasneh et al., 2021). García-Martínez et al. (2019) mention that devices for mobile learning enable learners builds their personal learning space. Indeed, learners can enjoy the flexibility that allows their schedule based on the requirements that suit their agenda (Mahasneh, 2020). In addition, learners can effectively balance their studies devoid of interrupting their present schedule. Moreover, the students learn to manage their time more effectively as well as be able to multitask. According to Letchumanan and Muniandy (2016), when learning or acquiring new things, the devices provide a newer boost to the learners' future careers with the careers starting to grow at last.

According to Castro et al. (2016), today, there are unlimited subjects that one can learn within the modern space, with individuals also being able of picking any subject that suits their interests as well as background. For example, if students or learners have an Information Technology background, the students can train in a 
different discipline such as Al, Tableau, or Salesforce. Indeed, according to Marquina (2018), when increasingly more courses emerge into the scene, learners must make good decisions that may help them achieve their preferred careers. There is usually no requirement to move from one particular area to another, a factor that helps save not just their time but also effort. As highlighted by Alpert (2016), Coman et al. (2020), Mohammadi et al. (2020), there are normally LIVE teacher-led classroom settings where learners can interact with their instructors directly and, even more, ask their questions quickly. In finding answers to the awareness and usage levels of mobile learning devices by students and student's acceptance of m-learning devices and technologies, the following research questions were derived from the literature review:

RQ1. What is the level of students' awareness of m-learning devices and technologies used for academic purposes?

RQ2. What are the types of m-learning devices and technologies predominantly used by students for academic purposes?

\section{M-learning Devices and Technologies Usefulness in Academia}

As stated by Ally and Prieto-Blázquez (2014), the devices facilitating mobile learning within higher learning can benefit learners in multiple ways. Firstly, it enables learners to conduct their learning in groups or even request customized sessions where the unit content is specifically designed for them. LIVE tutor-led class sessions have more interaction as compared to self-limited mobile learning. Coman et al. (2020) noted that teachers focus on learners' problems as well as their major interests more. Besides, they may better comprehend learners' strengths as well as weaknesses. According to Criollo-C et al. (2018), all kinds of mobile learning often provide learning materials in diverse forms, including MCQs, PPTs, blogs, whitepapers, assignments, articles, e-books, etc.

When classroom training is compared to virtual training, virtual training is normally less costly as well as affordable for learners, teachers, in addition to other individuals conducting other related tasks. Also, Ragusa and Crampton (2017) note that there are diverse payment options where learners may use to settle payments for their education services in installments. Today, loans targeted at students are usually available and learners do not need any form of interest or additional costs on installments. Indeed, for mobile learning, learners do not need to incur costs on books or any other related study materials. In general, it is relatively cheaper as well as more result-oriented. M-learning has indeed taken over from the traditional way of acquiring learning in which one has to acquire everything from the books. Mobile learning has also enabled learners to concentrate on specific modules that are of interest to them online. Besides, Brame (2015) states that educational materials are often available in diverse formats such as presentations and video content.

With the introduction of additional m-learning tools, learners may expect more exciting learning opportunities that can help them enhance their learning skills. Mobile learning use in higher learning offers learners the required confidence that will help them perform well not only during interviews but also when engaging in other discussions. As noted by Sung et al. (2016), mobile learning also empowers learners to present themselves with more confidence, in addition to shining out within a crowd.

Students who integrate mobile learning with classroom learning training are often more successful within their respective career paths. According to Díez-Echavarría et al. (2018), they normally attract higher remuneration packages as compared to their colleagues. Indeed, blended learning through the involvement of numerous mobile learning sessions not only provides constant support but also helps resolve the learners' queries promptly. Yilmaz et al. (2020) observe that various platforms that support mobile learning, including blogs, provide learners with important information and facts on why mobile learning forms the future of learning, especially higher education (Mahasneh, 2021).

According to Díez-Echavarría et al. (2018), m-learning usage in higher learning produces measurable and significant differences in terms of learners' engagement as well as performance. It minimizes the existing gap in terms of the delivery of learning as well as gives a different dimension to the important sector of higher education. Technology has undoubtedly transformed how learning is delivered as well as shared forever. It is inspiring learners to take their certificates as well as degree courses. Also, Badwelan et al. (2016) confirm that $\mathrm{m}$-learning use in higher learning establishments has been acknowledged by many owing to its widespread access as well as the plenty of gains it offers. 
Earlier, students within several higher learning institutions were unsure as to whether to accept the use of mobile learning devices. According to Ahmad (2020), this lack of confidence formed a major reason behind the students' reluctance to pursue their education through mobile learning. Abu-Al-Aish and Love (2013) observe that there are diverse views as to whether learners within various learning institutions across the world have adopted and acknowledged the usage of the devices supporting mobile learning in higher education. Scholars share a strong opinion that the acknowledgment, prominence, as well as popularity of the devices supporting m-learning, can offer varied resources to support learners within higher learning institutions expand their minds regardless of where they are (Mohammadi et al., 2020).

Yilmaz et al. (2020) also note that mobile learning devices can also be effectively used to support the blended learning type of approach. Instructors may ask questions or probe individuals during in-person training sessions and the audience may respond to them through a survey taken through their smartphones (Yilmaz et al., 2020). Given this, the trainer may share or provide the link relating to the survey, request or invite participants to take part via email, or develop a QR code that they may easily capture using their smartphone cameras. According to Ahmad (2020), and Yilmaz et al. (2020), one can easily obtain an immediate response, which is particularly effective when teaching larger groups. Thus, the reviewed literature on the perceived ease of use and the perceived usefulness of mobile learning attempts to answer the following research question:

RQ3. What is the perceived usefulness of these m-learning devices and technologies for academic purposes among students in Ghana?

\section{Limitations of Using M-learning Devices and Technologies in Higher Educational Institutions}

Lack of mobile networks within various surroundings forms part of the major limitations in the usage of mobile learning gadgets. As highlighted by Criollo-C et al. (2018) and Kankam (2020), the inadequacy of cellular network exposure or connection letdown in wireless communication forms a more commonly debated methodological issue of mobile technology, with Mohammadi et al. (2020) also stating that the comparatively small size of the screen of many mobile gadgets forming another crucial problem to m-learning gadgets reception. This directs to an additional idea, the little usability of mobile gadgets caused by low coverage of cellular networks, non-durable battery life as well as small screens and keyboards.

To add to, the high expenses related to positioning mobile systems for education, Criollo-C et al. (2018) and Mohammadi et al. (2020) note that additional issues associated with mobile gadgets include content supply to the user, network accomplishment, and content heterogeneity. The number two factor established is that all education applications have used usability assessments, neither do we discover guides or structures to assess them. It can create issues with several users who are not so conversant with mobile expertise and hence have restrictions on their relations and understanding of training applications (Brantes Ferreiram et al., 2013; Demuyakor, 2021). This indicates an urgent requirement to expand the knowledge among learners using smartphones as a form of m-learning.

Finally, m-learning gadgets may be unsuited to social and traditional standards. For instance, mobile gadgets can be observed as sources of interruption, both by learners and teachers, which may impact academic accomplishment. Mobile education gadgets can be an excessive interruption (Dontre, 2021). Mobile learning gadgets can be disrupted if the operators get consistently distracted by text messages and reports (Dontre, 2021). It then needs self-control and emphases some training institutions report that the cooperative academic usage of mobile expertise happens to a restricted extent, learning and physical interaction with specialists hardly arises. This could be a risk that could damage their learning value. The achievement of $\mathrm{m}$ learning arouses learners to new undesirable anticipation as learners feel that they are necessary to make extra energies to master m-learning expertise (Milosevic et al., 2015). The following research question is used to find out limitations of using m-learning devices and students' acceptance: 


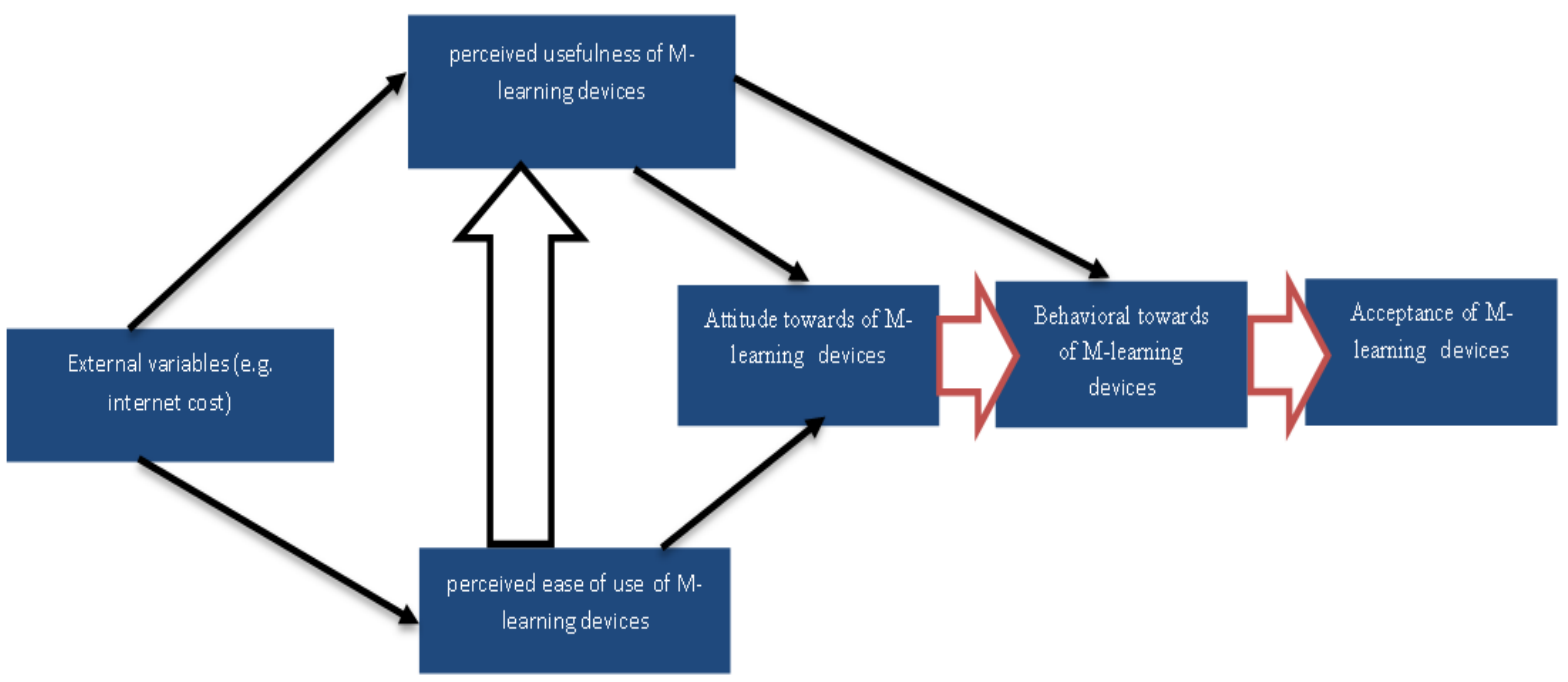

Figure 1. Minor modification of the basic technology acceptance model (Davies, 1989)

RQ4. What are the limitations of the usage of these m-learning devices and technologies among students?

\section{Theoretical Framework}

Globally, advances in science have resulted in massive technological transformations in higher education. Consequently, the utilization of mobile learning technologies within higher educational institutions has become increasingly essential mobile learning technologies through the Internet support online and offline sharing of course contents, and digitally organized communication structures within the higher educational institutions (Mohammadi et al., 2020). Again, the use of mobile learning technologies in the provision of teaching and learning services faces various obstacles, including end-user acceptance. According to Davies (1989), the Technology Acceptance Model (TAM) is a model that was established in the late 1980s as a means of studying digital technology adoption and usage (Davies, 1989). This model proposes that when users are offered a new technology, their use is dependent on several factors. Among these factors include behavioral intentions, attitude, and supposed convenience of the system, perceived ease of use of the innovation, individual user's intention, and facilitating organizational condition (Figure 1).

The attitude of a user towards technology or innovation is dependent on whether the user will utilize or reject the innovation. The attitude of the user, in turn, is influenced by (a) perceived efficacy and (b) perceived simplicity in terms of use, with a direct effect on perceived usefulness and ultimately improving performance (Lai, 2019). The perceived usefulness and perceived simplicity are measured by external variables such as cost of data, availability of facilities, and associated challenges of the technology or innovation (Davies, 1989).

Davies (1989) noted that the end-user's intention to use an innovation establishes two major factors that influence the approval of an application; perceived usefulness and perceived ease of application. Again, Davies (1989) highlighted that the TAM was developed from the Theory of Reasoned Action, a theory that aims at explaining users' behavior. The model thus serves to predict consumers' acceptance, assess, and substantiate already accepted innovations. With TAM as a foundation model from several innovation adoptions and acceptance studies, the present study adopted TAM as the main theoretical framework to assess mobile learning technologies' adoption and usage by students in the three topmost universities in Ghana. Adoption of TAM for this study allowed for the inclusion of three major research questions and five hypotheses with the specific objectives of establishing acceptance and usage levels of mobile learning technologies by students in three universities in Ghana. 
Table 1. Descriptive statistics of the participants

\begin{tabular}{|c|c|c|c|}
\hline \multicolumn{4}{|c|}{ University of Ghana } \\
\hline Variables & Subgroups & Frequency $(n=307)$ & Percentage (\%) \\
\hline \multirow[t]{3}{*}{ Age (years) } & $21-30$ & 223 & 72.6 \\
\hline & $31-40$ & 76 & 24.7 \\
\hline & $41-50$ & 8 & 2.6 .1 \\
\hline \multirow[t]{3}{*}{ Gender } & Male & 212 & 40.8 \\
\hline & Female & 95 & 53.8 \\
\hline & Others & NA & NA \\
\hline \multirow[t]{4}{*}{ Education } & Master's degree (or higher) & 14 & 4.5 \\
\hline & Bachelor's degree & 188 & 61.2 \\
\hline & Diploma & 88 & 28.6 \\
\hline & Others & 17 & 5.5 \\
\hline \multicolumn{4}{|c|}{ University of Education, Winneba } \\
\hline Variables & Subgroups & Frequency $(\mathrm{n}=376)$ & Percentage (100\%) \\
\hline \multirow{3}{*}{ Age (years) } & $21-30$ & 254 & 67.5 \\
\hline & $31-40$ & 113 & 30.0 \\
\hline & $41-50$ & 9 & 2.3 \\
\hline \multirow[t]{3}{*}{ Gender } & Male & 194 & 51.5 \\
\hline & Female & 180 & 47.8 \\
\hline & Others & 2 & 0.5 \\
\hline \multirow[t]{4}{*}{ Education } & Master's degree (or higher) & 8 & 2.1 \\
\hline & Bachelor's degree & 234 & 62.2 \\
\hline & Diploma & 101 & 26.8 \\
\hline & Others & 33 & 8.7 \\
\hline \multicolumn{4}{|c|}{ Tamale Technical University } \\
\hline Variables & Subgroups & Frequency $(n=376)$ & Percentage (100\%) \\
\hline \multirow[t]{3}{*}{ Age (years) } & $21-30$ & 203 & 58.6 \\
\hline & $31-40$ & 144 & 41.4 \\
\hline & $41-50$ & NA & NA \\
\hline \multirow[t]{3}{*}{ Gender } & Male & 213 & 61.3 \\
\hline & Female & 134 & 38.7 \\
\hline & Others & NA & NA \\
\hline \multirow[t]{4}{*}{ Education } & Master's degree (or higher) & 13 & 3.9 \\
\hline & Bachelor's degree & 198 & 57.0 \\
\hline & Diploma & 71 & 20.4 \\
\hline & Others & 65 & 18.7 \\
\hline
\end{tabular}

\section{MATERIALS AND METHODS}

\section{Study Area and Participants}

This study was conducted in three cities of Ghana. Participants were $(N=1,030)$ students from three conveniently sampled universities in three cities of Ghana. Out of a population of $(\mathrm{N}=1,030)$ students, the University of Ghana had $29.8 \%$ ( $n=307)$, University of Education, Winneba had $36.5 \%(n=376)$ of the sampled population, and Tamale Technical University (33.7\%(n=347), respectively. The comparative analysis of the demographic characteristics of respondents is reported by condensed Table 1, describing the universities and the sample of students who participated (with their characteristics).

\section{Recruitment and Procedure}

Participants were recruited through the class WhatsApp group of students from the three sampled universities in three cities (Accra, Winneba, and Tamale) in Ghana. The researchers contacted the administrators of each group and first to explain the objectives and scope of the study and to seek their consent and approval to use their platforms to collect the data. After receiving the consent and approval from members of the year group was briefed by the researchers and administrators further explained the objectives of the study, after which a good number of members volunteered to participate in the study. The data collection instrument was designed with the QuestionPro survey tool and the link to the data collection tool was shared on each group's page for the volunteers to complete. The respondents were assured of their 
anonymity and the data collected were meant for only academic purposes. The data collection lasted for three months, in May, June, and July 2021.

\section{Instruments for Data Collection, Validity, and Reliability}

A QuestionPro survey tool was employed to design the data-gathering instrument. The survey questions enabled the researchers to probe further, understand, and explore respondents' contributions. The datagathering instrument was made up of seven sections. The first section covered the demographic characteristics of respondents. Section 2 focused on awareness and usage and the types of mobile learning technologies used among respondents. The remaining two sections focused on items related to perceived usefulness and limitations of mobile learning technologies with a five-point Likert scale (1=strongly disagree, $2=$ somewhat disagree, 3=neither disagree nor agree, $4=$ somewhat agree, and $5=$ strongly agree).

To ensure the meticulousness and integrity of the study, and consequently guarantee the credibility of the research findings, various steps were undertaken to improve the reliability of this particular study (O'Connor \& Joffe, 2020). Firstly, the data-collection tool was pre-tested with a sample of 150 participants to assess the validity and reliability of the instruments from Cape Coast Technical University in the central region. Thereafter, factor analysis (Kaiser-Meyer-Olkin (KMO) index and Bartlett test of Sphericity) and Cronbach's alpha coefficient conducted in SPSS were used to determine the questionnaire validity and its reliability, respectively. The KMO index and Bartlett test had Sphericity for the 28 items on the questionnaire, ranging from $0.50-0.98$ with a p-value of significance at 0.01 for validity. Conversely, Cronbach's alpha coefficient for 28 items was 0.76 which was slightly above the acceptable threshold of 0.73 (Thorsen \& Bjorner, 2010).

\section{Measures: Definition of M-learning Devices or Technologies}

According to Romero-Rodríguez et al. (2020), the learning that is done or mediated through mobile digital devices or technologies for knowledge acquisition, and enhancing digital competence is what is termed as $\mathrm{m}$ learning. For m-learning in higher educational institutions, the focus is mostly on applying Information Communication Technologies (ICT) to promote autonomy and collaborative learning between students and teachers.

The instrument for the measurement of the level of awareness, the researchers adopted the five dimensions' measurement proposed by Kim et al. (2006), Sarrab et al. (2015), and Walton et al. (2005), which include; $N A=$ Not Aware, $S A=$ Somewhat Aware, NS=Not Sure, $A=$ Aware, VA=Very Aware. The instrument consisted of 10 items identified to evaluate students' actual knowledge relating to m-learning devices and technologies adopted in higher education.

The researcher adopted a five-point Likert scale (1=strongly disagree, 2=somewhat disagree, 3=neither disagree nor agree, $4=$ somewhat agree, 5=strongly agree) to aid in identifying the names or types of m-learning devices and technologies used by students.

This study conceptualized the question of perceived usefulness in three distinct measures. Thus, perceived usefulness about m-learning devices and technologies used by students is either for seeking information(academic), for entrainment or fun, and for building social relations among students. For this study, each of the dimensions is investigated from the perspective of m-learning devices and technologies applied for academic purposes. The research items, therefore, centered basically on how m-learning devices and technologies benefit students academically. A user's perceived usefulness of the m-learning devices and technologies is anchored on what these devices and technologies can offer them.

\section{Data Analysis}

Data collected were analyzed using percentages, frequencies, mean and standard deviation (SD) to establish discrepancies of mobile learning technologies awareness and usage. The t-test was used to establish the level of significance for each item at a $95 \%$ confidence interval. Standard descriptive data were employed in summarizing respondents' characteristics, as well as their usage of, and perception regarding mobile learning technologies used by students. The findings of the study were done by testing the suggested research model through Structural Equation Modelling. The regression analysis was carried out with the help of SmartPLS to assess the path coefficient of the data collected for the model. 


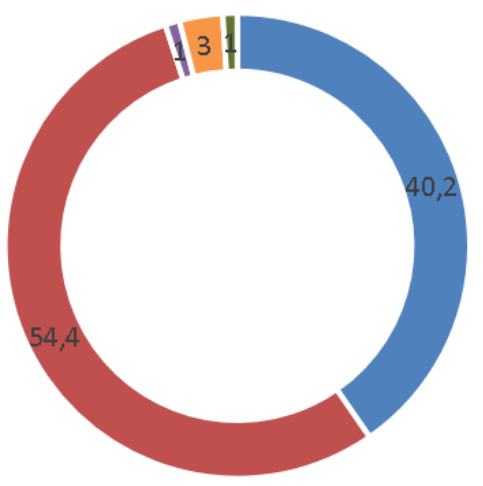

- A=Aware - VA=Very Aware $\quad \mathrm{NA}=$ Not Aware $\because \mathrm{SA}=$ Somewhat Aware $\quad$ NS=Not sure

Figure 2. Student's awareness levels of m-learning devices and technologies

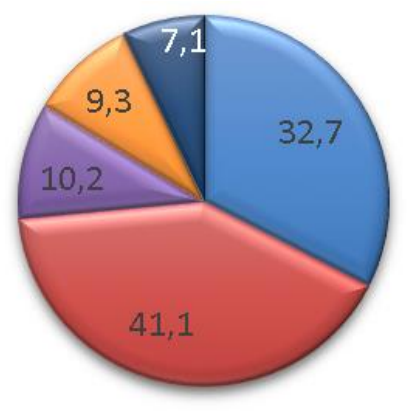
- Laptops
$\square$ Smartphones
Digital notebooks
$\square$ Tablets
athers

Figure 3. Types of m-learning devices and technologies used by students

\section{RESULTS}

\section{RQ1: Student's Awareness of M-learning Devices and Technologies Used for Academic Purposes by Students}

RQ1 has enabled the researchers to measure students' awareness from the perspective of actual levels of student's knowledge of various m-learning technologies used in higher education adopting the scale of measurement proposed by Kim et al. (2006), Sarrab et al. (2015), and Walton et al. (2005), which include; $N A=$ Not Aware, $S A=$ Somewhat Aware, $N S=$ Not Sure, $A=A$ ware, $V A=$ Very Aware. The responses from the participants indicated $(A=40.2 \%, V A=54.4 \%$, and the remaining $5.4 \%$ were those who are moderately aware of $m$-learning technologies). The findings revealed that $94.6 \%$ of the sampled students had considerable knowledge or are aware of them-learning devices and technologies used in higher educational institutions. The findings are illustrated in Figure 2.

\section{RQ2: Types of M-learning Devices and Technologies Used by Students for Academic Purposes}

RQ2 is intended to investigate the specific types of m-learning devices and technologies used by students in higher educational institutions. The names or types of the specific m-learning devices and technologies enabled the researchers to measure the actual m-learning devices and technologies used by students to carry out their academic needs. The findings from our responses indicated that the names or types of $\mathrm{m}$-learning devices and technologies reported by students are laptops (32.7\%), smartphones (41.1\%), tablets (9.3\%), digital notebooks (10.2\%), and others (7.1\%). The findings are indicated in Figure 3. 
Table 2. Descriptive statistics of perceived usefulness of m-learning devices for academic

\begin{tabular}{lrcc}
\hline & Perceived usefulness & M & SD \\
\hline 1 & M-learning devises or technologies content is designed in a concise and straightforward format. & 2.88 & 1.225 \\
2 & It's also possible to use mobile devices or technologies for a blended learning approach. & 2.96 & 1.461 \\
3 & M-learning devices or technologies enable students to take their learning materials with them. & 3.92 & 1.342 \\
4 & M-learning devices or technologies facilitate and speed up the feedback. & 3.08 & 1.103 \\
5 & Reach scattered students that are always on the go and need easy access to content. & 3.33 & 1.752 \\
6 & Offline m-learning provides support to download content and learn without access to the Internet. & 3.84 & 1.502 \\
Overall & 3.34 & 1.398 \\
\hline
\end{tabular}

M: Mean; SD: Standard deviation

Table 3. Descriptive statistics for limitations of for m-learning devices

\begin{tabular}{|c|c|c|c|}
\hline & Limitations & M & SD \\
\hline M- & 1-learning devices can be distracting if users get interrupted with text messages and notifications. & 2.76 & 1.522 \\
\hline 2 & M-learning devices can be limited by poor Internet infrastructure. & 3.89 & 1.422 \\
\hline 3 & Internet data is very expensive and prevent us from using m-learning devices. & 3.99 & 1.311 \\
\hline 4 & M-learning devices can be limited by security and privacy issues. & 3.33 & 1.212 \\
\hline Overall & & 3.65 & 1.385 \\
\hline
\end{tabular}

M: Mean; SD: Standard deviation

\section{RQ3: Perceived Usefulness of M-learning Devices for Academic Purposes}

Taken together, the item "m-learning platforms for academic purposes help in m-learning enables students to take their learning materials with them" had the highest average score $(M=3.92 ; S D=1.342)$ while the least item score came from "m-learning devices content is designed in a concise and straightforward format" with a mean of 2.88 and SD of 1.225. All the indicators on perceived usefulness of $\mathrm{m}$-learning platforms had an average score higher than 3.30 which was beyond the median of 3. This signifies that the perceived usefulness of m-learning platforms among the students is high (Table 2).

\section{QR4: Limitations of Accepting M-learning Devices and Technologies for Academic Purposes}

Taken together, the item "Internet data is very expensive and prevent us from using m-learning devices" had the highest average score ( $M=3.99 ; S D=1.311)$ while the least item score came from " $m$-learning devices can be distracting if your users get constantly interrupted with text messages and notifications" with a mean of 2.76 and SD of 1.522. All the indicators on limitations of m-learning devices had an average score higher than 3.60 which was beyond the median of 3 . This signifies that there is a high limitation of m-learning devices usage among the respondents (Table 3 ).

\section{Structural Equation Modelling (SEM) for Testing the Research Model (Figure 1)}

Further analysis was conducted in a separate model to assess the structural model using the data sample of all respondents. These analyses were conducted using the SmartPLS 3 application for Windows. A path/regression analysis was performed to determine the effect of independent variables ( $m$-learning devices awareness level, types of m-learning technologies, perceived usefulness of m-learning devices, perceived ease of use, and limitation of m-learning devices) on the dependent variable (Acceptance of m-learning devices).

The structural equation model is presented in Figure 4. The outcome of this model suggests the independent variables jointly contributed to $23.1 \%$ (R-square $=0.231$ ) of the variations in the dependent variable which is relatively low for the evaluation of the model. The effect of each independent variable on the dependent variable is also summarized in Table 4.

\section{The Output of Path/Regression Analysis}

Table 4 shows the regression analysis findings of the students' responses. The responses showed that usage behavior was substantially affected by the awareness level ( $p$-value $=0.122$ ) of the participants along with usage level ( $p$-value=0.322), perceived usefulness ( $p$-value=0.578), perceived ease of use $(p$-value 0.445$)$, and limitations ( $p$-value=0.351). Similar were the results for the impact of all the latent variables on themlearning acceptance by students in higher educational institutions in Ghana is R-square=0.231. 


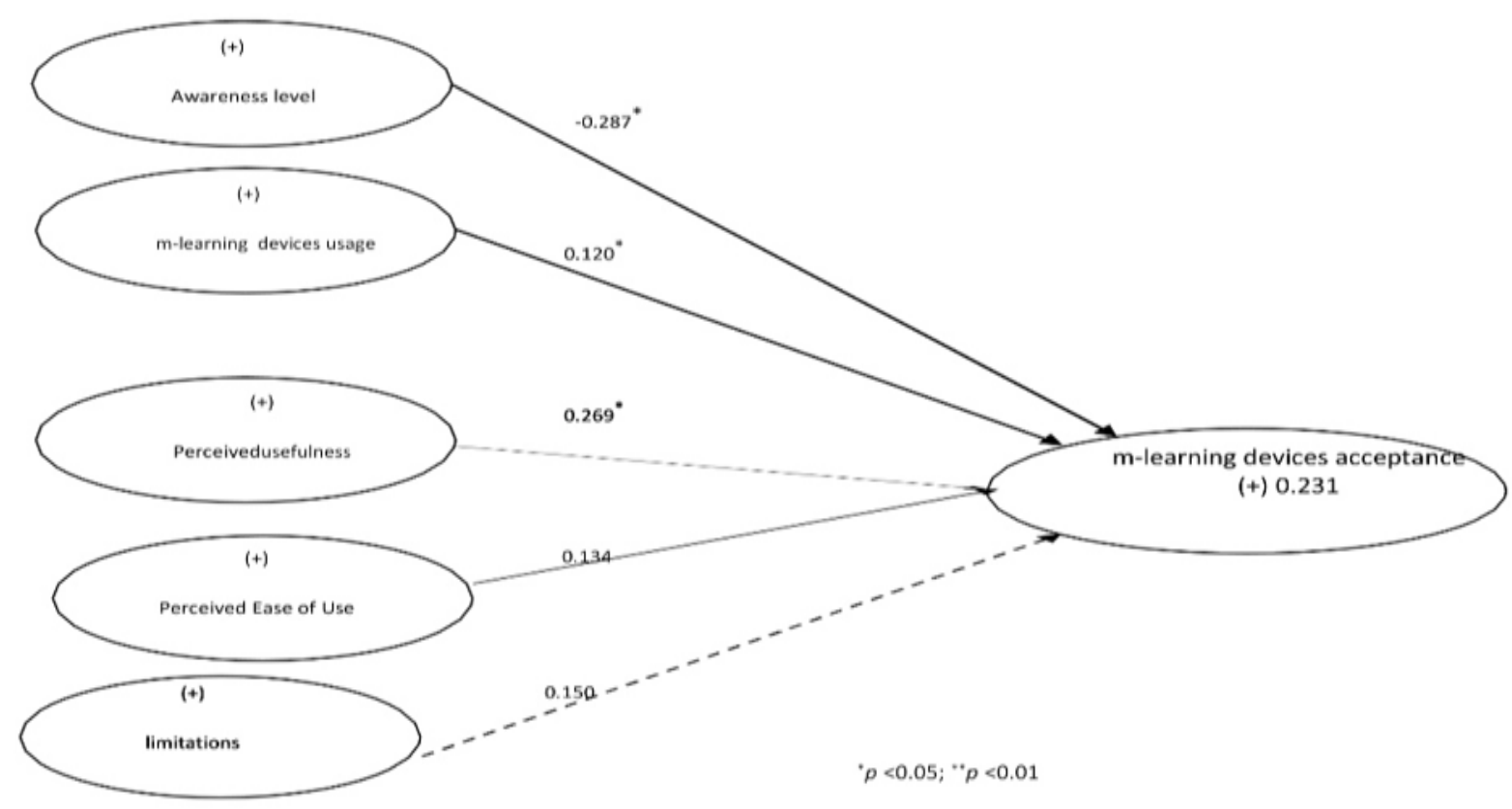

Figure 4. Structural equation model of independent and dependent variables of proposed research model

Table 4. Model equation variables

\begin{tabular}{lcccc}
\hline Latent variable & Path coefficient & t-statistic & p-value & Remarks \\
\hline Awareness level & -0.297 & 1.548 & 0.122 & Insignificant(-) (ve) effect \\
Usage level or user's level of experience & 0.120 & 0.992 & 0.322 & Insignificant+ (ve) effect \\
Perceived ease of use & 0.134 & 0.883 & 0.445 & Insignificant+ (ve) effect \\
Perceived usefulness & 0.269 & 0.557 & 0.578 & Insignificant+ (ve) effect \\
Limitations & 0.150 & 0.934 & 0.351 & Insignificant+ (ve) effect \\
\hline
\end{tabular}

R-square $=0.231$

\section{DISCUSSION}

The main objective of this study is to explore factors that influence students to accept m-learning devices using the TAM model. The study contributes to the literature central to the acceptance of m-learning devices by supplying a context-specific conceptual framework, which may affect the intention of the higher education students towards accepting m-learning tools. The study has developed the framework by applying the TAM theory, which is recognized as one of the utmost parsimonious technological and behavioral theories.

The study again hypothesized the impact of variables or construct that was used to attain an acceptance model which is in line with TAM. The finding is a clear indication that the main construct of the TAM model was matching with literature where limitations and other external influences are found to be the most prominent predictors of students' technological acceptance (Davies, 1989). The correlation results validate the study hypothesis showing that there is a substantial impact of study constructs with technological acceptance. The results are consistent with the previous finding, which shows that usage and behavioral intention are substantially related to each other (García-Martínez et al., 2019; Mohammadi et al., 2020). The acceptance is impacted due to different study variables and conditions of the individual students (Castro et al., 2016; Marquina, 2018).

The results of the study indicate that the acceptance of the use of m-learning devices by students is influenced by five key variables or constructs suggested in the research framework. The constructs, awareness level, usage level or user experience, and perceived ease of use were key variables in determining the level of acceptance of mobile learning devices in a higher educational institution in Ghana. The entire five variables that were identified were able to be sustained. This was a big sign of support for the study.

Another key predictor or factor that was also found to be significant in terms of m-learning devices' acceptance is the perceived ease of use of m-learning devices. Perceived ease of use of m-learning devices 
was found to be the third influencer in this study, possibly due to the ability of students to use m-learning devices with ease. To add to that, the respondents had that issues related to technology are important for the continuity of the usage of m-learning devices in learning due to the relationship between ease of use and acceptance. The perceived usefulness of m-learning devices is also a key factor in determining the level of acceptance among students. Availability of resources such as good Internet bandwidth and appropriate devices to access m-learning devices cannot be taken for granted for all potential users of $\mathrm{m}$-learning devices. Therefore, it will play a big role in determining m-learning acceptance. All these observations from the current study are in line with Ahmad (2020), Mohammadi et al. (2020), Ontiveros and Pazos (2013), and Vázquez Cano and Sevillano-García (2018) who all observed that the factors identified aids the acceptance of m-learning devices in higher educational institutions.

Understanding reasons for student adaptation is also crucial for delivering better results and acceptance of m-learning devices. Primarily, the two drivers observed include ease of use and perceived usefulness. There is a change in the education of students and the development of professional skills as the result of the rapid evolution of m-learning platforms in recent years (Díez-Echavarría et al., 2018). Therefore, there is a need for a multimedia m-learning devices teaching system for computer application courses in vocational colleges as experimental subjects (Criollo-C et al., 2018). The students interested in learning are likely to be provided with accessible, flexible, affordable, and fast-track completion of university courses through m-learning devices (Castro et al., 2016). The findings of the current study results are also endorsed by Castro et al. (2016), and Criollo-C et al. (2018), which showed that the acceptance of using m-learning devices is influenced by factors such as awareness level, usage level, perceived ease of use, and perceived usefulness.

\section{Theoretical and Practical Implications}

This paper contributes to technology in higher education by applying TAM to explore factors that influence students' acceptance of mobile learning devices for academic purposes. This current study tested the key variables of the TAM model to understand how limitations such as influence students' usage behavior mlearning devices and technologies in institutions of higher education. The results of the study have been able to extend the TAM model through finding out new moderating variables, for instance, the user's level of experience and understanding. Initial research discovered that the intentions of the users were based on their level of expertise in different areas (Castro et al., 2016; Díez-Echavarría et al., 2018), but whether this expertise could be applied based on TAM was not explored. This research confirms that under conditions of mobile learning devices usage, users differ according to their relative level of student's user experience.

Practitioners will discover that the outcome of the study gives some important understanding for employing mobile learning devices in higher education across the globe and Ghana in particular. The findings from this study suggest that the merits of m-learning platforms technology should be promoted and communicated. Managers of higher educational institutions in Ghana can also promote the positive effects of $\mathrm{m}$-learning devices. This can be done by inviting experienced practitioners and successful students who share their successful m-learning platforms experiences for motivating individuals to accept m-learning platforms. Similarly, different short videos can be used for demonstrating the benefits linked to m-learning devices usage for students and teachers. The academic institutions must formulate a group for answering students' queries related to m-learning devices usage. Accordingly, different seminars could be arranged for the students where different materials, benefits, and optimum use of m-learning platforms can be communicated.

\section{CONCLUSIONS, LIMITATIONS, AND FUTURE RESEARCH}

The study developed and tested the integrated model of TAM for technology acceptance among students. The study findings suggest that teachers should instigate efforts to improve the students' perception concerning the relevance of them-learning devices and technology adaptation in institutions of higher learning. The results further direct future researches to explore how students define success on a personal level. They must also explore how m-learning devices and technologies assist students in their learning while analyzing the factors that promote their engagement. It also suggests using the developed framework for identifying the unknown variables that might affect the use of m-learning devices among the participants. To 
understand the dynamics among students in the use of m-learning devices and technologies in higher education, the researchers proposed that future studies can conduct a comparative study on the perceived usefulness of m-learning devices and technologies between public and private universities.

In most cases, students who are selected to answer survey questions are always different from those who do not answer the questions. Therefore, it is essential to note that not all the answers can be generalized to represent students in various institutions of higher learning across Ghana. The limitation of the research work is that it was only carried out in three public universities in Ghana. Due to constraints beyond the reach of the researchers, all universities in Ghana could not be covered in this study, hence three universities and a few students were randomly selected for this study. For further research, it is recommended to conduct a largescale study in all the public universities in Ghana to understand factors that lead to mobile learning devices acceptance and their usage as well. To add to that, there is a possibility of extending the TAM with other variables or construct to create a better indulgence of m-learning devices' continuance in teaching and learning. Due to some limitations, future studies may shed more light on the use of mobile learning devices for improved academic productivity for both teachers and students.

Author contributions: All authors were involved in concept, design, collection of data, interpretation, writing, and critically revising the article. All authors approve final version of the article.

Funding: The authors received no financial support for the research and/or authorship of this article.

Declaration of interest: Authors declare no competing interest.

Data availability: Data generated or analysed during this study are available from the authors on request.

\section{REFERENCES}

Abu-Al-Aish, A., \& Love, S. (2013). Factors influencing students' acceptance of m-learning: An investigation in higher education. The International Review of Research in Open and Distributed Learning, 14(5), 83-107. https://doi.org/10.19173/irrodl.v14i5.1631

Ahmad, T. (2020). Student perceptions on using cell phones as learning tools: Implications for mobile technology usage in Caribbean higher education institutions. PSU Research Review, 4(1), 25-43. https://doi.org/10.1108/PRR-03-2018-0007

Al-Hamad, N. Q., AlHamad, A. Q., \& Al-Omari, F. A. (2020). Smart devices employment in teaching and learning: Reality and challenges in Jordan universities. Smart Learning Environments, 7(1), 5. https://doi.org/ 10.1186/s40561-020-0115-0

Ally, M., \& Prieto-Blázquez, J. (2014). Quin és el futur de l'aprenentatge mòbil en l'educació? [What is the future of mobile learning in education?] RUSC. Revista de Universidad y Sociedad Del Conocimiento [University and Knowledge Society Magazine], 11(1), 142. https://doi.org/10.7238/rusc.v1111.2033

Alpert, F. (2016). Revitalizing the live lecture class with instructor-created videos. SAGE Open, 6(4), 215824401668068. https://doi.org/10.1177/2158244016680686

Alzaza, N. S., \& Yaakub, A. R. (2011). Students' awareness and requirements of mobile learning services in the higher education environment. American Journal of Economics and Business Administration, 3(1), 95-100. https://doi.org/10.3844/ajebasp.2011.95.100

Apuke, O. D., \& lyendo, T. O. (2018). University students' usage of the internet resources for research and learning: Forms of access and perceptions of utility. Heliyon, 4(12), e01052. https://doi.org/10.1016/ j.heliyon.2018.e01052

Badwelan, A., Drew, S., \& Bahaddad, A. A. (2016). Towards acceptance m-learning approach in higher education in Saudi Arabia. International Journal of Business and Management, 11(8), 12. https://doi.org/ 10.5539/ijbm.v11n8p12

Brame, C. J. (2015). Effective educational videos. Vanderbilt University. https://cft.vanderbilt.edu/guides-subpages/effective-educational-videos

Brantes Ferreira, J., Zanela Klein, A., Freitas, A., \& Schlemmer, E. (2013). Mobile learning: Definition, uses, and challenges. In L. A. Wankel, \& P. Blessinger (Eds.), Cutting-edge technologies in higher education (pp. 4782). Emerald Group Publishing Limited. https://doi.org/10.1108/S2044-9968(2013)000006D005 
Cassidy, E. D., Colmenares, A., Jones, G., Manolovitz, T., Shen, L., \& Vieira, S. (2014). Higher education and emerging technologies: Shifting trends in student usage. The Journal of Academic Librarianship, 40(2), 124133. https://doi.org/10.1016/j.acalib.2014.02.003

Castro, J., Yamada, G., \& Arias, O. (2016). Higher education decisions in Peru: On the role of financial constraints, skills, and family background. Higher Education, 72(4), 457-486. https://doi.org/10.1007/ s10734-016-0040-x

Chand, P., \& Arora, J. (2008). Access to scholarly communication in higher education in India: Trends in usage statistics via INFLIBNET. The Program, 42(4), 382-390. https://doi.org/10.1108/00330330810912061

Coman, C., Țîru, L. G., Meseșan-Schmitz, L., Stanciu, C., \& Bularca, M. C. (2020). Online teaching and learning in higher education during the coronavirus pandemic: Students' perspective. Sustainability, 12(24), 10367. https://doi.org/10.3390/su122410367

Criollo-C, S., Lujan-Mora, S., \& Jaramillo-Alcazar, A. (2018). Advantages and disadvantages of m-learning in current education. 2018 IEEE World Engineering Education Conference (pp. 1-6). https://doi.org/10.1109/ EDUNINE.2018.8450979

Davis, F. D. (1989). A technology acceptance model for empirically testing new end-user information systems: Theory and result in a doctoral dissertation. MIT Sloan School of Management.

Demuyakor, J. (2021). COVID-19 pandemic and higher education: Leveraging on digital technologies and mobile applications for online learning in Ghana. Shanlax International Journal of Education, 9(3), 26-38. https://doi.org/10.34293/education.v9i3.3904

Díez-Echavarría, L., Valencia, A., \& Cadavid, L. (2018). Mobile learning on higher educational institutions: How to encourage it? Simulation approach. DYNA, 85(204), 325-333. https://doi.org/10.15446/dyna.v85n204. 63221

Dontre, A. J. (2021). The influence of technology on academic distraction: A review. Human Behavior and Emerging Technologies, 3(3), 379-390. https://doi.org/10.1002/hbe2.229

García-Martínez, I., Fernández-Batanero, J. M., Cobos Sanchiz, D., \& Luque de la Rosa, A. (2019). Using mobile devices for improving learning outcomes and teachers' professionalization. Sustainability, 11(24), 6917. https://doi.org/10.3390/su11246917

Kankam, P. K. (2020). Mobile information behaviour of sandwich students towards mobile learning integration at the University of Ghana. Cogent Education, 7(1), 1796202. https://doi.org/10.1080/2331186X.2020. 1796202

Kim, S. H., Mims, C., \& Holmes, K. P. (2006). An introduction to current trends and benefits of mobile wireless technology use in higher education. AACE Journal, 14(1), 77-100.

Lai, Y.-H. (2019). The application of meta-analytic SEM on exploring factors that influence teachers' usage of interactive whiteboard. Pedagogical Research, 4(3), em0038. https://doi.org/10.29333/pr/5854

Letchumanan, M., \& Muniandy, B. (2016). How do mathematics postgraduate students use mobile e-book? Library Hi Tech News, 33(7), 6-7. https://doi.org/10.1108/LHTN-02-2016-0009

Mahasneh, O. (2021). Factors that affect university college students' acceptance and use of mobile learning (MI). International Journal of Instruction, 14(3), 861-872. https://doi.org/10.29333/iji.2021.14350a

Mahasneh, O. M. (2020). The effect of teaching by (mobile learning) in university students 'achievement. Proceedings of the 6th International Conference on Mobile Learning 2020 (pp. 121-125). https://doi.org/ 10.33965/ml2020_202004C017

Mahasneh, O. M., Tawarah, H. M., \& Al-lawama, H. A. (2021). Using structural equation model to reveal factors affecting faculty members in university colleges in the use of Moodle. International Journal of Education and Practice, 9(1), 171-184. https://doi.org/10.18488/journal.61.2021.91.171.184

Marquina. P. F. (2018). Developing world-class students in Peru. GlobalFocus. https://www. globalfocusmagazine.com/developing-world-class-students-in-peru/

Milošević, I., Živković, D., Manasijević, D., \& Nikolić, D. (2015). The effects of the intended behavior of students in the use of m-learning. Computers in Human Behavior, 51, 207-215. https://doi.org/10.1016/j.chb.2015. 04.041

Mohammadi, M., Sarvestani, M. S., \& Nouroozi, S. (2020). Mobile phone use in education and learning by faculty members of technical-engineering groups: Concurrent mixed methods design. Frontiers in Education, 5, 16. https://doi.org/10.3389/feduc.2020.00016 
Mpungose, C. B. (2020). The emergent transition from face-to-face to online learning in a South African University in the context of the Coronavirus pandemic. Humanities and Social Sciences Communications, 7(1), 113. https://doi.org/10.1057/s41599-020-00603-x

Mynbayeva, A., Sadvakassova, Z., \& Akshalova, B. (2018). Pedagogy of the twenty-first century: Innovative teaching methods. In O. B. Cavero, \& N. Llevot-Calvet (Eds.), New pedagogical challenges in the 21st centuryContributions of research in education. InTech. https://doi.org/10.5772/intechopen.72341

O'Connor, C., \& Joffe, H. (2020). Intercoder reliability in qualitative research: Debates and practical guidelines. International Journal of Qualitative Methods, 19, 160940691989922. https://doi.org/10.1177/ 1609406919899220

Okoye, K., Rodriguez-Tort, J. A., Escamilla, J., \& Hosseini, S. (2021). Technology-mediated teaching and learning process: A conceptual study of educators' response amidst the COVID-19 pandemic. Education and Information Technologies, 26, 7225-7257. https://doi.org/10.1007/s10639-021-10527-x

Ontiveros, M., \& Pazos, J. R. C. (2013). Education and technology in Mexico and Latin America: Outlook and challenges. RUSC. Revista de Universidad y Sociedad Del Conocimiento [University and Knowledge Society Magazine], 10(2), 163-169. https://doi.org/10.7238/rusc.v10i2.1848

Peters, K. (2007). M-learning: Positioning educators for a mobile, connected future. The International Review of Research in Open and Distributed Learning, 8(2). https://doi.org/10.19173/irrodl.v8i2.350

Ragusa, A. T., \& Crampton, A. (2017). Online learning: Cheap degrees or educational pluralization? Cheap degrees or educational pluralization? British Journal of Educational Technology, 48(6), 1208-1216. https://doi.org/10.1111/bjet.12489

Romero-Rodríguez, J.-M., Aznar-Díaz, I., Hinojo-Lucena, F.-J., \& Cáceres-Reche, M.-P. (2020). Models of good teaching practices for mobile learning in higher education. Palgrave Communications, 6(1), 80. https://doi.org/10.1057/s41599-020-0468-6

Sarrab, M., Al-Shihi, H., \& Khan, A. I. (2015). An empirical analysis of mobile learning (m-learning) awareness and acceptance in higher education. 2015 International Conference on Computing and Network Communications (pp. 960-963). https://doi.org/10.1109/CoCoNet.2015.7411307

Sharma, S. K., Joshi, A., \& Sharma, H. (2016). A multi-analytical approach to predict Facebook usage in higher education. Computers in Human Behavior, 55, 340-353. https://doi.org/10.1016/j.chb.2015.09.020

Sung, Y.-T., Chang, K.-E., \& Liu, T.-C. (2016). The effects of integrating mobile devices with teaching and learning on students' learning performance: A meta-analysis and research synthesis. Computers \& Education, 94, 252-275. https://doi.org/10.1016/j.compedu.2015.11.008

Thorsen, S. V., \& Bjorner, J. B. (2010). Reliability of the Copenhagen psychosocial questionnaire. Scandinavian Journal of Public Health, 38, 25-32. https://doi.org/10.1177/1403494809349859

UNESCO. (2015, February 27). Mobile technology is the key to bringing 'education to all', says UN Broadband Commission. UNESCO. https://en.unesco.org/news/mobile-technology-key-bringing-education-all-saysbroadband-commission

Vázquez Cano, E., \& Sevillano-García, M. ${ }^{a}$ L. (2018). Ubiquitous educational use of mobile digital devices. A general and comparative study in Spanish and Latin American higher education. Journal of New Approaches in Educational Research, 7(2), 105-115. https://doi.org/10.7821/naer.2018.7.308

Walton, G., Childs, S., \& Blenkinsopp, E. (2005). Using mobile technologies to give health students access to learning resources in the UK community setting. Health Information and Libraries Journal, 22(s2), 51-65. https://doi.org/10.1111/j.1470-3327.2005.00615.x

Yilmaz, Y., Suner, A., \& Yilmaz, O. (2020). Mobile learning in a flipped classroom: Findings from a "5-lecture-5" blended learning design for large classes. Turkish Journal of Biochemistry, O(0), 20190417. https://doi.org/10.1515/tjb-2019-0417

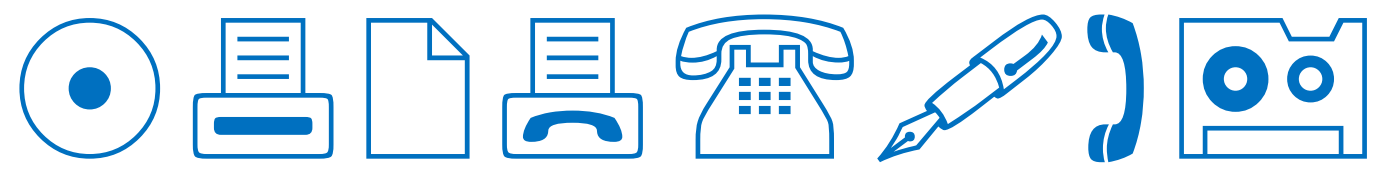

